\title{
Avaliação sorológica de anticorpos para Leishmania spp. na população canina em região de foco de leishmaniose tegumentar americana na Lomba do Pinheiro, Porto Alegre, Rio Grande Do Sul, Brasil
}

\author{
JAIRO RAMOS DE JESUS*, FLÁVIO ANTÔNIO PACHECO DE ARAUJO*, \\ SILVIA SPALDING***, e FÁTIMA TIECHER ****
}

\begin{abstract}
SEROLOGICAL EVALUATION FOR ANTIBODIES AGAINST Leishmania SPP. IN A CANINE POPULATION FROM A TEGUMENTARY LEISHMANIOSIS FOCUS IN LOMBA DO PINHEIRO, PORTO ALEGRE, RIO GRANDE DO SUL, BRASIL
\end{abstract}

The leishmaniosis is a parasitic disease caused by a protozoan from the genus Leishmania spp., wich is considered in expansion in Brazil. In 2002 it was notify the first autochthonous human case of American tegumentary leishmaniasis (ATL) in a district of Porto Alegre, State of Rio Grande do Sul, Brazil. Presently, 17 human cases were notified until November 2005, and there are many suspect cases, waiting for the diagnostic confirmation, converting this State in a risk area for the ATL. In the urban area, the dog plays an important role, acting as a source of infection and reservoir of this protozoan. Therefore a serological evaluation was done in 200 domicilliary dogs in a $1 \mathrm{~km}$ radius from 3 autochthonous human cases that occurred at the Rincão Road, located at the region of Lomba do Pinheiro, Porto Alegre district, Rio Grande do Sul State, Brazil. The Indirect immunofluorescent reaction (IFR) was used for the serologic diagnosis of the dogs. The seroprevalence of Leishmania spp. antibodies was 3,5\% (7/200), considering that from all the positives, 6 were male individuals and 1 was a female. Using the Fischer's Accurate Test for the statistical analysis, it was observed a significant association $(p=0,0484)$ between positives to the IFR and the gender of the animals. It was evidenced that males are 7 times (odds-ratio $=7,624)$ more predisposed to this infection than the females. The human presence plus the detection of Leishmania spp. antibodies in the canine population, demonstrates that the participation of the dogs occurs in the epidemiologic cycle of this disease in the urban focus from the Rincão Road.

Key words: Leishmania, Leishmaniosis, Dogs, Survey.

\footnotetext{
* PPGCV DA FAVET/UFRGS.

** Laboratório de Protozoologia - FAVET/UFRGS.

*** Diretora Técnica do IPB-LACEN/RS.

***** Laboratório de Parasitología - IPB/LACEN/RS.
} 


\section{INTRODUÇÃO}

A leishmaniose é uma doença causada por protozoário digenético, pertencente à Ordem kinetoplastida, incluídos na Família Trypanossomatidae e no Gênero Leishnamia ${ }^{1}$. Sendo considerada uma das principais doenças transmitidas por vetores no mundo, no Brasil, é considerada em expansão, já que, com o crescimento dos centros urbanos e as dificuldades sócio-econômicas não se encontra mais confinada as floresta e matas, ocorrendo também nas periferias e nos centros urbanos. Surgindo, assim, uma cadeia epidemiológica urbana, onde os principais fatores de risco envolvidos são: a grande presença de hospedeiros silvestres e domésticos, diferentes espécies de flebotomineos vetores e histórico de leishmaniose na vizinhança $\mathrm{a}^{2-4}$.

A forma tegumentar da doença, é patologia espectral, polimórfica de pele e mucosa que acomete o homem e diversos animais, incluindo o cão ${ }^{5}$. No Brasil o número de novos casos anuais de leishmaniose Tegumentar Americana (LTA) em humanos é estimado em 30.000 casos/ano e até o momento existem 7 espécies responsabilizadas pela LTA no Brasil: Leishmania (Viannia) brasiliensis; L. (V.) guyanensis; L. (V.) lainsoni; L. (V.) shawi; L. (V.) naifi; L. (V.) lindenbergi e L. (Leishmania) amazonensi ${ }^{2,6}$.

Até o ano de 2002, somente o Estado do Rio Grande do Sul (RS) não era considerado área de risco para a doença, porém, nesse mesmo ano ocorreu a notificação do primeiro caso autóctone de LTA em humanos, no município de Porto Alegre, capital do Estado. Atualmente, já foram notificados 17 casos autóctones no Estado, além de vários casos suspeitos transformando o RS em área de risco para a doença ${ }^{6}$. A participação de animais domésticos no ciclo epidemiológico da LTA é conhecida há muito tempo e diversos estudos em áreas endêmicas demonstraram que, tanto o jumento (Equus asinus) quanto o cão são, frequentemente, encontrados infectados pelo agente $^{7}$. No RS as ações de controle e prevenção de LTA por parte da Divisão de Vigilância Ambiental em Saúde, incluem o fornecimento de medicamento para LTA; capacitação das regionais em epidemiologia com relação à situação do agravo no Estado; capacitação de entomologistas na captura e identificação dos vetores; levantamento da fauna de flebotomineos; capacitação de médicos veterinários da região metropolitana de Porto Alegre na identificação de LTA em animais domésticos e, por fim, projeto de estudo sobre reservatórios de Leishmania spp. nas áreas onde houve casos de LTA, com objetivo de determinar os agentes envolvidos na transmissão desse agravo. Uma vez que, segundo a Coordenadoria Geral de Vigilância em Saúde (CGVS) da Secretaria Municipal da Saúde de Porto Alegre, não estando concluído o mapeamento de possíveis vetores e hospedeiros, não se conhece totalmente o comportamento da doença e o risco de transmissão da mesma ${ }^{6,8}$.

O presente trabalho tem por objetivo avaliar a soroprevalência de anticorpos de Leishmania spp. na população canina de uma área de foco de LTA, em Porto Alegre, onde ocorreram 12 casos em humanos no período de 2000 a 2005.

\section{MATERIAIS E MÉTODOS}

Descrição da Área: A Estrada do Rincão, local escolhido para o presente estudo por apresentar pelo menos 5 casos confirmados dos 12 ocorridos na região; entre 2000 e 2005, fica na divisa dos Bairros Lomba do Pinheiro, Restinga e Belém Novo. Bairros situados na região sudeste do município de Porto Alegre, capital do RS. As habitações do local se localizam nas encostas de morros circundadas por resquícios de mata nativa ou em áreas de mata nativa desmatada para a realização da agricultura de pequeno porte. A região tem, além das pequenas lavouras, a criação de suínos como fonte de renda, e por ser uma área de periferia, é normal a presença de lixões a céu aberto e um grande número de cães errantes, provenientes do abandono ou/e da reprodução descontrolada.

Delimitação da Área de Estudo: Foram selecionados por conveniência 3 casos humanos, dos registrados na Estrada do Rincão, e conforme recomendação da FUNASA em 1996 com relação a surtos de leishmaniose, realizada a delimitação de 1 raio de $1 \mathrm{~km}$ a partir de cada 1 dos 3 casos. Os 3 raios de ação cobriam uma distância de 4 $\mathrm{km}$ e uma vez delimitado o perímetro de trabalho, todas as residências dentro deste foram visitadas e os moradores que possuíam cães domiciliados, convidados a participarem, voluntariamente, do estudo.

Coleta de Material e Exame dos Animais: No período de março a abril de 2005, foram 
coletadas 200 amostras de sangue provenientes de animais (109 fêmeas e 91 machos) domiciliados dentro do perímetro de trabalho, previamente traçado. A coleta de sangue foi realizada por punção das veias Jugular ou Cefálica, após assepsia previa, utilizando seringa de $3 \mathrm{ml}$ com agulhas hipodérmicas calibre 0,7 $\mathrm{mm} \times 25 \mathrm{~mm}$. O volume total das amostras coletadas variava entre 1 a $2 \mathrm{ml}$. Após a coleta, os animais eram clinicamente inspecionados quanto à presença de lesões compatíveis com LTA, tendo em vista que, em áreas endêmicas, a porcentagem de cães assintomáticos é considerável. Adotou-se como único critério de seleção, o fato dos cães independentes de sintomatologia clínica, serem domiciliados dentro do perímetro de trabalho. A participação dos cães no estudo foi garantida mediante a assinatura, pelos proprietários, do termo de consentimento informado, esclarecendo sobre a doença e os objetivos do trabalho, o qual foi aprovado pelo Comitê de Pesquisa e pela Comissão de Ética da Universidade Federal do Rio Grande do Sul, Faculdade de Veterinária (UFRGS/FAVET).

As amostras de sangue eram colocadas em tubos de ensaio sem anti-coagulante, identificados com o nome do animal doador e armazenados em bolsas térmicas com gelo em gel para, posteriormente, serem centrifugadas e os soros, armazenados em flaconetes, congelados a $-20{ }^{\circ} \mathrm{C}$ até a realização da IFI. Todas as informações de identificação dos animais (sexo, raça, idade, pelagem), assim como dos seus proprietários, foram anotadas em planilhas para controle dos resultados e para posterior repasse de informações.

Imunofluorescência Indireta para leishmaniose Tegumentar Canina: $O$ teste de Imunofluorescência Indireta (IFI) usado para o estudo foi cedido pelo setor de reativos do BioManguinhos, Instituto Oswaldo Cruz, Rio de Janeiro. O "Kit" continha: 4 frascos de antígeno de Leishmania; 1 frasco de glicerina tamponada; 1 frasco de Azul de Evans; 1frasco de conjugado anti-cão-FITC; 4 caixas de lâminas pra IFI e manual de instruções. $\mathrm{O}$ antígeno utilizado eram as formas promastigotas da espécie L.(V.) brasiliensis. Os soros testados foram diluídos em razão 2, nas diluições 1:40 e 1:80, os controles negativo e positivo foram diluídos em 1:40, sendo o controle positivo, obtido de cães positivos para
LTA, cordialmente cedidos pelo Laboratório de Protozoologia da Fundação Oswaldo Cruz. A diluição de 1:40 foi adotada como ponto de corte do teste, sendo considerados positivos, soros com fluorescência maior ou igual a 1:40. A confecção das lâminas, titulação dos soros controles e leituras das amostras foram realizadas no Laboratório de Parasitologia da Fundação Estadual de Produção e Pesquisa em Saúde (FEPPS), Instituto de Pesquisas Biológicas (IPB), Laboratório Central do Estado do Rio Grande do Sul (LACEN/RS).

Análise Estatística: Para análise estatística foram utilizados o Teste do Qui-quadrado e o Teste Exato de Fisher, através do uso do programa de análises estatísticas Instat ${ }^{\circledR}$. As análises foram realizadas relacionando a positividade na IFI com o sexo, a raça e a idade dos animais.

\section{RESULTADOS}

Apresentaram positividade para anticorpos de Leishmania spp. 7 das 200 amostras de soros analisados, evidenciando soroprevalência de $3,5 \%$. Nenhum dos animais participantes do estudo apresentou lesões compatíveis ou sugestivas de LTA e somente 1 cão era domiciliado junto a caso humano da doença e outro em uma distância menor do que 200 metros da residência de outro caso. Os 5 restantes, embora domiciliados dentro do perímetro de trabalho, não estavam diretamente relacionados às residências dos casos humanos ocorridos na região. Com relação à titulação apresentada pelas amostras positivas, 5 apresentaram reatividade apenas na diluição de 1:40 e somente 2 reagiram nas diluições de 1:40 e 1:80.

Dentre as amostras positivas, 6 eram provenientes de caninos machos e 1 de uma fêmea. Com relação à idade, 3 soros pertenciam a animais com 2 anos de idade, 1 soro a um com 10 anos, 2 a cães com 6 anos e 1 amostra a um animal de 4 anos de idade. Com relação à raça, 5 dos positivos não apresentavam raça definida (S.R.D) e 2 eram da raça Pastor Alemão (P.A). $\mathrm{Na}$ tabela abaixo podemos visualizar os dados descritos reunidos: Tabela 1 .

O Teste do Qui-quadrado foi utilizado para verificar a existência de associação significativa entre a idade (em meses) e a positividade na IFI. Para isso, os 200 animais foram divididos em 4 grupos distintos pela idade em meses $(0-24 ; 25$ - 
Tabela 1. Demonstrativo entre as características (Idade em Anos; Sexo e Raça) e a positividade na IFI para Leishmaniose Tegumentar Canina, no período de março de 2005

\begin{tabular}{rcrcc}
\hline Amostras Positivas & Diluição & Idade & Sexo & Raça \\
\hline 4 & $1: 80$ & 2 & $\mathrm{M}$ & S.R.D \\
28 & $1: 40$ & 10 & $\mathrm{M}$ & S.R.D \\
86 & $1: 80$ & 4 & $\mathrm{M}$ & P.A \\
88 & $1: 40$ & 6 & $\mathrm{M}$ & P.A \\
169 & $1: 40$ & 2 & $\mathrm{~F}$ & S.R.D \\
173 & $1: 40$ & 2 & $\mathrm{M}$ & S.R.D \\
184 & $1: 40$ & 6 & $\mathrm{M}$ & S.R.D \\
\hline
\end{tabular}

48; 49-72; mais de 72), com um $\mathrm{p}=0,7079$; observou-se não haver associação significativa entre idade e positividade. O Teste Exato de Fisher foi aplicado na busca de associação significativa entre a positividade na IFI e a raça dos animais, sendo estes divididos em 2 grupos denominados Sem Raça Definida (S.R.D) e Com Raça Definida (C.R.D). Com um p $=0,7045$, não foi encontrado associação significativa entre esses parâmetros. O mesmo teste foi utilizado para analise da relação entre a positividade e o sexo dos cães participantes, com um $\mathrm{p}=0,0484$, houve associação significativa entre as características, onde se observou uma predisposição 7 vezes maior (odds-ratio $=7,624$ ) dos machos à infecção.

\section{DISCUSÃO}

Grande parte dos estudos envolvendo técnicas sorológicas incluem a IFI, sendo essa, assim como o ELISA, técnica com alta sensibilidade para o diagnostico de anticorpos de Leishmania spp $^{9-11}$. As sorologias detectam a maioria dos cães sintomáticos e grande parte dos assintomáticos e a pesquisa de anticorpos em áreas endêmicas vem sendo realizada com IFI e títulos significativos tem sido encontrados em cães com ou sem sinais clínicos ${ }^{9,12}$.

Com relação à soroprevalência encontrada de $3,5 \%$, estudos têm demonstrado variação nos resultados. Pesquisa de anticorpos na população canina em área endêmica no Paraná revelou uma soroprevalência de $18,2 \%$ de anticorpos para Leishmania em uma população de 132 cães investigados ${ }^{12}$. Em outro estudo, agora em município endêmico para LTA no Rio de Janeiro, foi observada a soroprevalência de 8,9\% em 98 cães de área endêmica sub-urbanizada e 39,4\% em 40 animais estudados, em área endêmica rural $^{13}$. Na Grécia, pesquisa realizada com cães sem sinais clínicos, domiciliados em área endêmica, evidenciou $12,3 \%$ de positividade para anticorpos de Leishmania spp., em uma população de 73 cães, através da $\mathrm{IFI}^{9}$. Na região Sul, no estado do Paraná, em uma população de 159 cães foi observada uma prevalência de anticorpos de $4,4 \%{ }^{11}$. Todos os estudos acima citados utilizaram ponto de corte na diluição de 1:40.

Embora as soroprevalências citadas sejam maiores do que a do presente trabalho, acreditamos ser a soroprevalência de 3,5\% bastante significativa, pois é comum que os testes sorológicos apresentem algumas falhas na detecção de animais infectados no período prépatente e antes da soroconversão, assim como dos soropositivos que negativam, mas permanecem infectados trazendo dados subestimados para os estudos epidemiológicos de soroprevalência ${ }^{9}$. Além de ser verificado que cães com sorologia reagente muitas vezes não apresentam sinais clínicos, atuando, no entanto, como bons reservatórios, com grande poder de infectar o vetor da doença ${ }^{14}$.

Com relação aos valores próximos ao ponto de corte que foram encontrados na maioria das amostras positivas no nosso estudo, esses já foram observados por outros pesquisadores que em seus estudos encontraram reatividade sorológica nas diluições de 1:40 e 1:80 na maioria das sorologias realizadas ${ }^{10,12,13}$. É fato consumado que valores sorológicos estão intimamente relacionados com a forma de LTA envolvida, a gravidade e o número de lesões encontradas, ocorrendo títulos maiores em casos de envolvimento mucoso e de 
lesões múltiplas com grande comprometimento cutâneo ${ }^{3}$.

Outra informação considerada importante é o fato de que apenas 1 cão sorologicamente positivo era domiciliado junto a caso humano de LTA e outro em uma distância menor do que 200 metros da residência de outro caso. Os outros 5 animais positivos são domiciliados dentro do raio de 1 $\mathrm{Km}$ dos casos humanos, porém, não em residências onde a doença ocorreu em humanos. Esses dados nos levam a pensar que no foco de LTA na região da Lomba do Pinheiro, Estrada do Rincão, o cão ainda não tenha o papel de principal fonte de infecção para humanos, não fazendo a ligação entre o foco silvestre (zoonótico) e o urbano (antroponótico), não vinculando a infecção no peri e intra-domicílio. Nesse caso, devido à proximidade das residências com a mata nativa, tanto os cães quanto às pessoas estariam se infectando a partir da picada do inseto vetor que têm como reservatório vertebrado, um outro animal, provavelmente silvestre, responsável pela infecção do vetor e manutenção do foco da doença. Desse modo, o cão tem participação secundária no ciclo silvestre que ocorre na região, porém fica a pergunta, de por quanto tempo o cão ainda permaneceria nesse papel, pois é sabido que o mesmo apresenta potencial para se tornar a principal fonte de infecção no meio urbano e tem sido assim responsabilizado ${ }^{7}$.

\section{RESUMO}

Através da realização do estudo podemos concluir que $3,5 \%$ dos cães estudados apresentaram positividade na IFI; a soropositividade baixa associada ao fato de os animais positivos terem sido assintomáticos, não descartam o seu papel como fonte de infecção e potencial risco à saúde pública. Assim sendo, os resultados encontrados evidenciam a possibilidade da existência do protozoário na população canina da região, tornando necessárias novas pesquisas, utilizando técnicas diagnósticas mais sensíveis, para comprovação dos resultados obtidos.

\section{REFERENCIAS}

1.- LAINSON R, SHAW J J. Leishmaniasis in Brasil: V. Studies on the epidemiology of cutaneous leishmaniasis in Mato Grosso Sate, and observations on two distinct strains of Leishmania isolated from mam and forest animals. Trans Roy Soc Trop Med Hyg 1970; 64: 65467.

2.- SOUZA A I, BARROS E M S, ISHIKAWA, et al. Feline leishmaniasis due to Leishmania (Leishmania) amazonensis in Mato Grosso do Sul State, Brazil. Vet Parasitol 2005; 128: 41-5.

3.- MANUAL de controle da Leishmaniose tegumentar americana. Brasília: Ministério da Saúde, 2000. 62 p.

4.- JESUS J R de. Avaliação Sorológica para anticorpos de Leishmania spp. através da reação de Imunofluorescência Indireta na população canina da região da Lomba do Pinheiro, cidade de Porto Alegre, RS, Brasil, a partir de casos autóctones humanos de Leishmaniose Tegumentar.2006. 80f. Dissertação (Mestrado em Parasitologia). Universidade Federal do Rio Grande do Sul, Porto Alegre, 2006.

5.- GENARO O. Leishmaniose Tegumentar Americana. In: NEVES, D.P. Parasitologia Humana. 10.ed. São Paulo: Atheneu. 2002. p. 36-53.

6.- SANTOS E, ALMEIDA M A B, SOUZA, et al. Situação da Leishmaniose Tegumentar Americana no Rio Grande do Sul. Bol Epidem - centro estadual de vigilância em saúde/RS. 2005ª ; : 1-3.

7.- FALQUETO A, COURA J R, BARROS G C, et al. Participação do cão no ciclo de transmissão da Leishmaniose tegumentar no Município de Viana, Estado do Espírito Santo, Brasil. Mem Inst Oswaldo Cruz Rio de Janeiro 1986; 81: 155-63.

8.- ALERTA sobre transmissão autóctone de Leishmaniose cutâneo mucosa no município de Porto Alegre. Bol Epid Secretaria Municipal Saúde de Porto Alegre 2002; 5: $1-5$.

9.- LEONTIDES S L, SARIDOMICHELAKIS M N, BILLINIS C, et al. A cross-sectional study of Leishmania spp. infection in clinically healthy dogs with polymerase chain reaction and serology in Greece. Vet Parasitol 2002; 109: 19-27.

10.- ROMERO G A S, ORGE M G O, GUERRA M V F, et al. Antibody response in patients with cutaneous leishmaniasis infected by Leishmania (Viannia) brasiliensis or Leishmania (Viannia)guyanensis in Brasil. Acta Trop 2005; 93: 49-56.

11.- CASTRO E A, LUZ E, TELLES F Q, et al. Ecoepidemiological survey of Leishmania (viannia) braziliensis American cutaneous and mucocutaneous leishmaniasis in Ribeira Valley River, Paraná State, Brazil. Acta Trop 2005; 93: 141-9.

12.- SILVEIRA T G, TEODORO U, LONARDONI M V $\mathrm{C}$, et al. Investigação sorológica em cães de área endêmica de leishmaniose tegumentar, no estado do Paraná, Sul do Brasil. Cadernos Saúde Pública, Rio de Janeiro 1996; 12: 89-93.

13.- SANTOS G P L, SANAVRIA A, MARZOCHI M C A, et al. Prevalência da infecção canina em áreas endêmicas de leishmaniose tegumentar americana, do município de Paracambi, Estado do Rio de Janeiro, no período entre 1992 e 1993. Rev Soc Bras Med Trop 2005b; 38

14.- BRASIL, Ministério da Saúde. Nota Técnica. Vacina anti-leishmaniose visceral canina Leshimune. Brasília, D.F., 29 set. 2005. Disponível em: < http:// portal.saude.gov.br/portal/arquivos/pdf/lvc-notatecnica.pdf>. Acesso em: 05 out. 2005. 